\title{
KLEBSIELLA SEROTYPES IN INFECTIONS OF THE EAR AND UPPER RESPIRATORY TRACT
}

\author{
BY \\ SAMUEL S. EPSTEIN AND I. FRIEDMANN \\ From the Department of Pathology of the Institute of Laryngology and Otology, London
}

(RECEIVED FOR PUBLICATION DECEMBER 12, 1957)

The carbohydrate nature of the Klebsiella capsule was first demonstrated by Toenniessen $(1912,1921)$. However, as recently emphasized by Tomcsik (1956), he was unaware of its antigenic reactivity. The serological specificity of capsular polysaccharide was described by Heidelberger and Avery (1923, 1924). On the basis of this work, Julianelle (1926) demonstrated three capsular types, A, B, and C, and a heterogeneous group $X$, including several untyped strains. The source of Julianelle's strains was mainly sputum from cases of human pneumonia. Type $\mathrm{C}$ has subsequently been associated with rhinoscleroma. Gastings and Snijders (1936) later extended these types to six, by describing three additional types, $D, E$, and $F$, isolated from cases of ozaena. In Kauffmann's (1949) classification, these types are designated $1-6$ and subsequently discovered types by higher numerals. Including the three types recently described by Ørskov (1955a), the present number of serotypes has reached a total of 72. Although these have been isolated from a wide variety of sources, there is general agreement that the lower types, especially 1-6, are far more frequently recovered from the respiratory tract than elsewhere in the body. Henriksen (1954a), analysing 46 sputum strains, found that $54 \%$ were lower types. Similarly Edwards and Fife (1955) showed that $53 \%$ of 199 sputum and $90 \%$ of 20 nasopharyngeal strains belonged to types $1-6$. There are, however, obvious regional differences in the distribution of individual types, as, in Copenhagen,
Ørskov (1955b) found that the classical respiratory types $1-6$ were only represented by $15.6 \%$ of 102 sputum strains.

It is proposed here to present a serological analysis of Klebsiellae isolated from common infections of the ear and upper respiratory tract and also to assess their frequency of incidence.

\section{Material}

The 50 strains of Klebsiellae studied in this series were isolated in the course of routine bacteriological examination of the material received in the Pathology Department over a period of 14 months (October, 1955November, 1956). Strains were selected for study on the basis of their biochemical criteria, irrespective of whether or not they exhibited the mucoid colonial morphology of typical Klebsiellae. These criteria included such recently developed investigations as the cyanide, gluconate, and a amino-acid decarboxylase tests and are discussed elsewhere (Epstein, 1958a).

\section{Serotyping Technique}

Before serotyping, all strains were subcultured for 18 hours on lactose agar plates (lactose $0.5 \%$, peptone $0.5 \%$. As emphasized by Duguid (1948) and Edmunds (1954), the high carbohydrate nitrogen ratio of this medium is favourable to capsule formation, yet tends to discourage the production of excessive slime. Wet collargol mounts were prepared from each strain and examined with a $1 / 6$ objective, to determine the presence or absence of capsules. No attempt was made to type

TABLE I

BACTERIOLOGICAL ANALYSIS OF OTITIS AND SINUSITIS

\begin{tabular}{|c|c|c|c|c|c|c|c|c|c|c|}
\hline & \multirow[b]{2}{*}{$\begin{array}{c}\text { No. of } \\
\text { Cases }\end{array}$} & \multicolumn{9}{|c|}{ Bacteriology ( $\%)$} \\
\hline & & $\begin{array}{l}\text { Staphylo- } \\
\text { coccus } \\
\text { pyogenes }\end{array}$ & $\begin{array}{c}\text { Strepto- } \\
\text { coccus } \\
\text { pyogenes }\end{array}$ & $\begin{array}{c}\text { Streptococ- } \\
\text { cus pneu- } \\
\text { moniae }\end{array}$ & B. proteus & $\begin{array}{c}\text { Ps. } \\
\text { pyocyanea }\end{array}$ & $\begin{array}{l}\text { Escher- } \\
\text { ichiae }\end{array}$ & $\begin{array}{l}\text { Kleb- } \\
\text { siellae }\end{array}$ & $\begin{array}{c}\text { Haemo- } \\
\text { philus }\end{array}$ & $\begin{array}{l}\text { Mixed and } \\
\text { Miscel- } \\
\text { laneous }\end{array}$ \\
\hline $\begin{array}{l}\text { Acute otitis media . } \\
\text { Recurrent otitis media } \\
\text { Chronic otitis media } \\
\text { Otitis externa } \\
\text { Sinusitis } \quad .\end{array}$ & $\begin{array}{l}534 \\
269 \\
562 \\
183 \\
324\end{array}$ & $\begin{array}{l}25 \cdot 3 \\
32 \cdot 4 \\
28 \cdot 4 \\
34 \\
19 \cdot 4\end{array}$ & $\begin{array}{l}20 \\
14 \cdot 5 \\
6 \cdot 0 \\
5 \cdot 0 \\
11\end{array}$ & $\begin{array}{r}7 \cdot 9 \\
7 \cdot 9 \\
1.8 \\
0 \cdot 9 \\
16 \cdot 4\end{array}$ & $\begin{array}{r}6 \cdot 4 \\
7 \cdot 3 \\
27 \cdot 6 \\
22 \cdot 4 \\
6 \cdot 5\end{array}$ & $\begin{array}{r}9 \cdot 9 \\
4 \cdot 6 \\
11 \cdot 5 \\
11 \cdot 6 \\
2.6\end{array}$ & $\begin{array}{l}5 \cdot 5 \\
3 \cdot 3 \\
7 \cdot 6 \\
4 \cdot 5 \\
7 \cdot 8\end{array}$ & $\begin{array}{l}1 \cdot 4 \\
1 \cdot 3 \\
1 \cdot 8 \\
1 \cdot 4 \\
3 \cdot 1\end{array}$ & $\begin{array}{l}3 \cdot 5 \\
7.9 \\
1.6 \\
11\end{array}$ & $\begin{array}{l}20 \cdot 1 \\
20 \cdot 8 \\
13 \cdot 7 \\
20 \cdot 2 \\
22 \cdot 2\end{array}$ \\
\hline
\end{tabular}


acapsulate strains. Capsulate strains were typed by capsular swelling tests, using pure capsular sera types 1-10 inclusive. The term "capsular swelling" is used here without prejudice, as Klieneberger-Nobel (1948) and Duguid (1951), among other workers, have shown that there is no true swelling when capsulated

TABLE II

DESCRIPTION OF KLEBSIELLA STRAINS ANALYSED

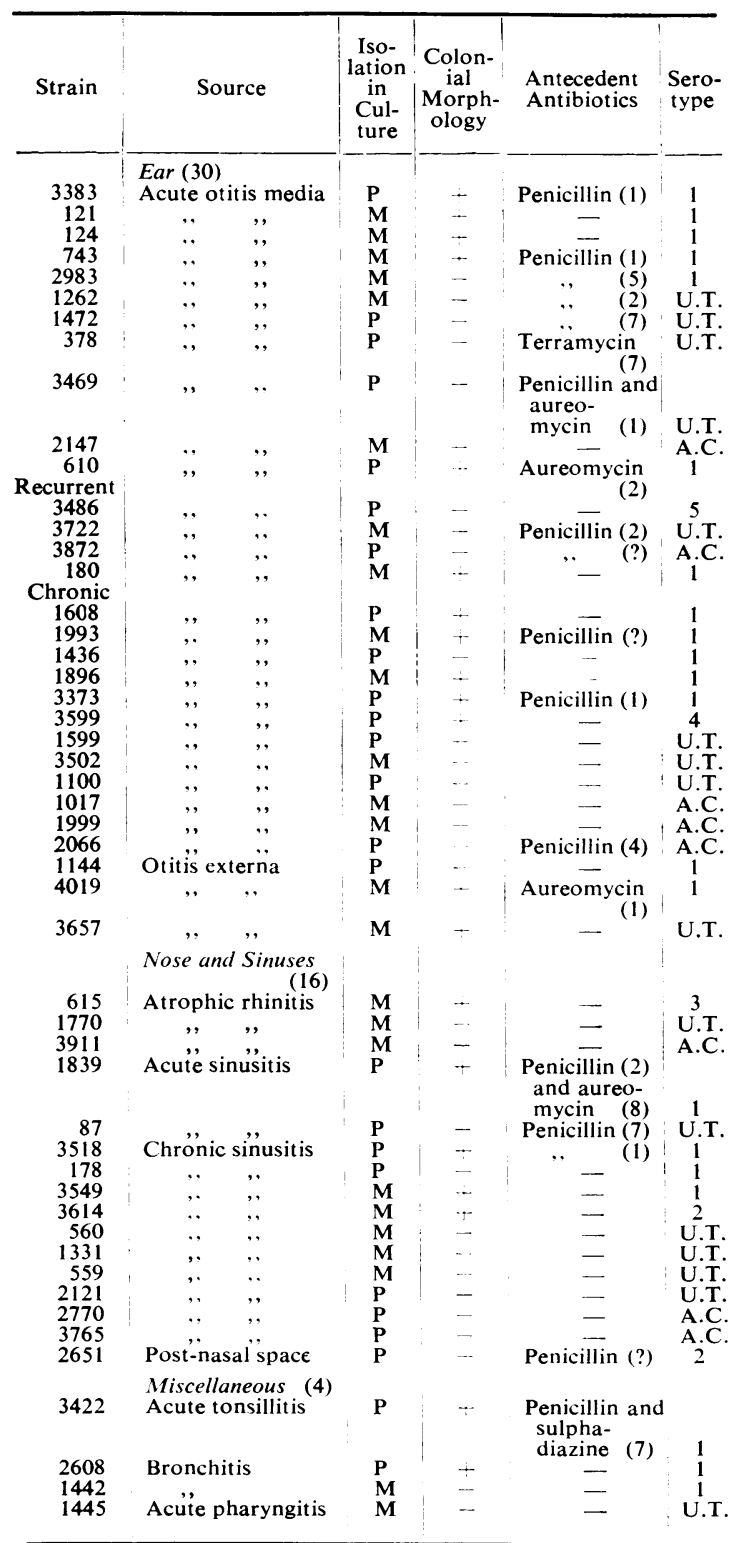

U.T. $=$ Untypable strains. A.C. $=$ Acapsulate strains. $+=$ Mucoid and tenacious colonies. $-\rightarrow$ Non-mucoid and non-tenacious colonies. $\mathbf{P}=$ Isolated in pure culture. $\mathbf{M}=$ Isolated in mixed culture. Figure in brackets denotes duration in days of antibiotic administration. organisms are placed in their homologous sera. In fact a precipitin reaction occurs at the surface of the capsule, which then becomes visible due to an increase in its refractility.

Edwards and Fife (1952) have stressed that antibody deviation may occur with high antigen concentrations. For this reason, saline suspensions were adjusted to an approximate density of 10 organisms per $1 / 6$ objective field. Further, as recommended by these authors, only freshly prepared suspensions were used.

Loopfuls of sera and suspension were mixed and mounts examined after five-minute intervals. Capsular titres were not estimated. The serological identity of each type was checked by absorption tests with homologous strains from the National Collection of Type Cultures. Sera were absorbed with strains under test for 30 minutes at $37^{\circ} \mathrm{C}$. The subsequent recovery of sera by centrifugation was facilitated by the use of minimal quantities of antigen. Mutual cross-absorption tests, the final proof of identity as emphasized by Edmunds (1957), were not performed.

\section{Results}

The majority of strains studied in this series were isolated from cases of otitis or sinusitis, a bacteriological analysis of which is presented in Table I. As can be seen, the approximate incidence of Klebsiellae in this material is $2 \%$. Table II presents a description of these strains with particular reference to their source of origin, antecedent antibiotic history, and serotype. In $48 \%$ of cases the strains were isolated in pure culture, in $22 \%$ with pathogenic staphylococci, and in the remainder with a variety of other organisms. Table III, based on

TABLE III

DISTRIBUTION OF STRAINS WITH REFERENCE TO STATE OF ISOLATION IN CULTURE

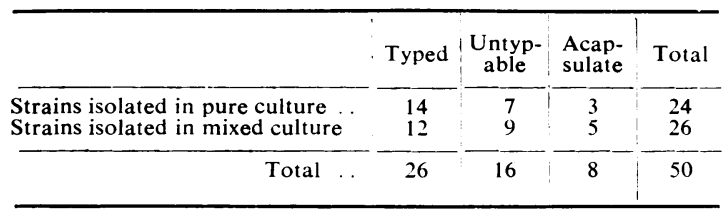

data derived from Table II, indicates that approximately half of the typed, untypable, and acapsulate strains respectively, were isolated in pure culture. Antibiotics were administered previously in $38 \%$ of cases, but in only $12 \%$ did the duration of therapy exceed four days. It is of interest to note that $40 \%$ of the total number of strains and $73 \%$ of the typed strains respectively exhibited a mucoid and tenacious colonial morphology.

As shown in Table II, eight strains were acapsulate and 16 untypable with the available sera. Twentysix strains were typed, of which 21 were found to 
belong to type 1. Absorption tests demonstrated the ability of these 26 strains to deplete their type sera of antibody to homologous N.C.T.C. strains.

\section{Discussion}

The series presented here is based on an analysis of strains mainly isolated from clinically defined infections of the upper respiratory tract and its extensions. Using sera types $1-10,62 \%$ of the capsulate strains were typable. Henriksen (1954a), on the other hand, using as many as 61 type sera, found that only $54 \%$ of 189 capsulate strains could be typed. His series, however, was heterogeneous, and included strains derived from urine, faeces, and water as well as sputum.

The value of Klebsiella typing has recently been challenged by Henriksen (1954b), who stressed that the increase in the number of serotypes has imposed serious practical limitations on this procedure. $\mathrm{He}$ also indicated the limited reproducibility of serological results and the increasing number of cross-reactions between closely related types. Edmunds (1957), however, suggested that some of these difficulties may well be due to non-specific reactions. He pointed out that, as Henriksen (1954a) used prolonged immunization courses, there was the possibility of "undue development of antibody to minor antigenic constituents." It is furthermore doubtful whether capsular titrations enhance the specificity of serotyping, quite apart from the additional labour involved. Edwards and Fife (1952) and Ørskov (1955c) are in agreement that absorption tests are of greater value than titrations in the confirmation of serological identity.

It is necessary to effect some compromise between the extreme that dismisses serotyping as impractical and the perfectionist attitude which insists that all 72 capsular sera, albeit in polyvalent pools, be employed and the results qualified by titrations or absorption tests.

Weiss, Eisenberg, Spirack, Nadel, Kayser, Sathavara, and Flippin (1956) recently maintained that types 1,2 , and 4 are rarely found in the respiratory tract, except in association with specific disease processes. They further indicated that the higher Klebsiella types may be found in the throat of healthy persons, and, as will subsequently be pointed out, this may occur especially after narrowspectrum antibiotic therapy. It would seem reasonable, therefore, to suggest that the routine laboratory restricts typing to a limited number of sera designed to include the common respiratory types. Henriksen (1954b) went so far as to suggest that if a strain isolated from the respiratory tract did not belong to one of the lower types, it was usually safe to assume that it exercised no aetiological role in the disease.

Authors such as Lipman, Coss, and Boots (1948) and Obrinsky, Dormont, Fowler, and Ruhstaller (1950) have minimized the primary role of Klebsiellae as causative factors of disease. They suggest that alleged recent increases in the incidence of Klebsiella infections can be ascribed to antibiotic superinfections. Weiss et al. (1956) agreed that antibiotic therapy is often associated with the emergence of Klebsiellae, but pointed out that these often proved to be higher types and of doubtful pathogenicity. Weinstein, Goldfield, and Chang (1954) indicated that superinfection rarely occurs unless antibiotic therapy has been prolonged for more than four days. This would imply that $88 \%$ of the strains isolated in this series are unlikely to have been secondary invaders. Furthermore, even in three of the six cases where antibiotics had been exhibited for over four days, the strains isolated proved to belong to lower types.

As indicated in Table III, approximately half of the strains in this series were isolated in pure culture. Even if in some of the remaining cases of bacteriologically mixed infections Klebsiellae did not constitute the predominant pathogens it would be difficult to deny them any aetiological role. It is, moreover, recognized procedure to treat mixed infections with antibiotics to which all isolated pathogens are sensitive, irrespective of the precise quantitative relationships which obtain in primary culture.

The relatively high incidence of acapsulate strains $-16 \%$ in this material-can be explained by the fact that selection was based on biochemical rather than morphological criteria. In most series the majority of acapsulate strains are automatically excluded from study, as they do not usually produce slimy mucoid colonies. Ørskov (1955c), in a recent investigation of faecal strains, found only two acapsulate out of a total of 76 strains. However, strains producing non-mucoid colonies were excluded from these studies. Bias of this type is equally apparent in Henriksen's (1954a) series. While it is true that such selection is likely to produce an abnormally high incidence of capsulate strains, yet, as emphasized by Edwards and Fife (1952), it must be appreciated that there is no correlation between a mucoid colonial morphology and the presence of capsules. In fact occasional acapsulate strains may be highly mucoid. In Kauffmann's (1949) classification of Klebsiella antigenic patterns, the latter is designated as MO (mucoid, acapsulate with $\mathrm{O}$ antigen), in contrast to the classical MKO form (mucoid, capsulate with $\mathrm{O}$ 
antigen). Kauffmann (1949) also showed that MO, unlike $\mathrm{MKO}$ forms, are susceptible to $\mathrm{O}$ agglutinins, although, as subsequently indicated by Edwards and Fife (1952), slime (M) and capsular (K) substances are serologically similar, if not identical.

Toenniessen (1915) demonstrated that acapsulate Klebsiellae could be highly virulent and concluded that the association between capsule formation and virulence was fortuitous. Topley and Wilson's Principles of Bacteriology and Immunity (Wilson and Miles, 1955) points out that "capsule formation is often associated with, but not essential to, virulence." Furthermore, as subsequently indicated, acapsulate Klebsiellae can act as respiratory tract pathogens in mice. Apart from this, it must be appreciated that three of the eight acapsulate strains in this series were isolated from clinically defined infections in a state of pure culture.

Primary Klebsiella (Friedlander) lung infections are well recognized clinical entities, which have recently been discussed by Erasmus (1956). He suggested that they probably represent a specific form of aspiration pneumonia, related to a precedent pharyngeal or middle ear infection with the same organism. There is also ample experimental evidence proving that Klebsiellae are capable of initiating infections of the respiratory tract and its extensions in animals. Hoyle and Orr (1945) and Sale and Wood (1947) demonstrated the ability of Klebsiellae to produce pneumonia in mice and rats inoculated by intranasal and intrabronchial techniques respectively. Using an intra-oral technique (Epstein, 1958b; Epstein and Stratton, 1958) representative strains of Klebsiellae in the present series and also other acapsulate strains (Epstein and Payne, 1958) have been shown to produce fatal pneumonic infections in anaesthetized mice. Furthermore, Friedmann $(1955,1957)$, in studies on experimental otitis in guinea-pigs, concluded that Klebsiellae can produce primary infections of the middle ear cleft. Thus both clinical and experimental studies confirm that these organisms may assume the role of respiratory tract pathogens.

\section{Summary}

The approximate incidence of Klebsiellae in clinically defined common infections of the upper respiratory tract and its extensions was found to be $2 \%$. Fifty strains of Klebsiellae isolated from these sites were examined. Only $40 \%$ of strains exhibited a mucoid and tenacious morphology. Using capsular sera types 1-10, 26 strains could be typed, of which 21 were found to belong to type 1 . Of the remainder, 16 strains were untypable and eight acapsulate.

There is suggestive evidence that the majority of these strains represented primary pathogens and not secondary invaders, consequent on antibiotic therapy.

The authors would like to express appreciation to Dr. P. R. Edwards, who supplied the capsular sera, and Dr. P. N. Edmunds for their generous help and advice and Mr. N. Spurling for technical assistance.

\section{REFERENCES}

Duguid, J. P. (1948). J. Path. Bact., 60, 265. (1951). Ibid., 63, 673.

Edmunds, P. N. (1954). J. infect. Dis., 94, 65.

- (1957). Personal communication.

Edwards, P. R., and Fife, M. A. (1952). J. infect. Dis., 91, 92. - (1955). J. Bact., 70, 382.

Epstein, S. S. (1958a). J. clin. Path. To be published.

- (1958b). J. Hyg. (Lond.), 56, 73.

- and Stratton, K. (1958). Ibid., 56, 80. and Payne, P. (1958). Unpublished data.

Erasmus, L. D. (1956). Quart. J. Med., 25, 507.

Friedmann, I. (1955). J. Laryng., 69, 27.

(1957). Personal communication.

Gastings, W. R., and Snijders, E. P. (1936). Zbl.Bakt.,Abt.1 (Orig.), 136,1 .

Heidelberger, M., and Avery, O. T. (1923). J. exp. Med., 38, 73. - (1924). Ibid., 40, 301.

Henriksen, S. D. (1954a). Acta path. microbiol. scand., 34, 249. - (1954b). Ibid., 34, 281.

Hoyle, L., and Orr, J. W. (1945). J. Path. Bact., 57, 441.

Julianelle, L. A. (1926). J. exp. Med., 44, 113.

Kauffmann, F. (1949). Acta path. microbiol. scand., 26, 381.

Klieneberger-Nobel, E. (1948). J. Hyg. (Lond.), 46, 345.

Lipman, M. O., Coss, J. A., Jr., and Boots, R. H. (1948). Amer. J. Med., 4, 702 .

Obrinsky, W., Dormont, R. E., Fowler, R. E. L., and Ruhstaller, F. (1950). Amer. J. Dis. Child., 80, 621.

Orskov, I. (1955a). Acta path. microbiol. scand., 36, 449.

- (1955b). Ibid., 36, 454.

- (1955c). Ibid., 36, 461 .

Sale, L., Jr., and Wood, W. B., Jr. (1947). J. exp. Med., 86, 239.

Toenniessen, E. (1912). Z Zbl. Bakt., Abt. 1 (Orig.), 65, 23. (1915). Ibid., 75, 329.

- (1921). Ibid., 86, 353.

Tomcsik, J. (1956). Bacterial Anatomy. Cambridge University Press, London.

Weinstein, L., Goldfield, J., and Chang, T. (1954). New Engl. J. Med., 251, 247 .

Weiss, W., Eisenberg, G. M., Spirack, A., Nadel, J., Kayser, H. L., Sathavara, S., and Flippin, H. L. (1956). Ann. intern. Med., 45, 1010 .

Wilson, G. S., and Miles, A. A. (1955). Topley and Wilson's Principles of Bacteriology and Immunity, 4th ed. Arnold, London. 